\title{
Retrospection of Errors and Feedback on Output of ESL/EFL Learners
}

\author{
Guilin Ma \\ School of Foreign Language, Huali College, Guangdong University of Technology \\ Zengcheng District, Guangzhou, Guangdong Province, China \\ E-mail: 973282253@qq.com
}

\begin{abstract}
This paper reviews the history and development of errors made by EFL/ESL learners; and it also examines the effects of error feedback from teachers and researchers. Specifically, this paper focuses on the studies concerning the different types of corrective feedback which give rise to more or less quality improvement in written or oral output of language learners. The results show that the effects of error feedback are subject to a series of interrelated factors, including learners' proficiency level, the nature of errors and the context of leaners' language. It is hoped that the findings of this paper may contribute to a deeper understanding of the characteristics of errors and feedback for both language learners and researchers.
\end{abstract}

Keywords-Learners; Error; Feedback; Output

\section{INTRODUCTION}

The issue of what prevents the smooth and successful development of learner proficiency has been a highly focused research project among different language classrooms. According to Allen et al's (1990) research findings, different types of classroom operations did not result in an expected significant effect on development of learner proficiency. That is, the differences between analysis (form) and experience (meaning) orientation in classroom did not make learners more excellent in grammar accuracy measures in the former and more competent in discourse and sociolinguistic measures in the latter. However, they did find the existence of satisfactory gains in one experience-oriented classroom alone. The researchers explained in terms of instruction quality which they claimed to correspond to Ellis's (1984) two hypotheses about what factors in classroom interaction effectively facilitated L2 development: one was consistent and accurate teacher feedback; the other was the classroom discussion of student errors committed in meaningful context.

\section{ERROR AND ERROR TYPES}

\section{A. Error}

Language error is defined as "unsuccessful bit of language" (James, 1998: 1), and error analysis is the process of settling the existence, the reasons and the affection of those unsuccessful language uses. In the phase of post error-analysis, "error" is considered to be an inappropriate term referring to the places or points in interlanguage system that mismatches the target language system. It was believed that learner language, even though including what was called "errors" had its own right to be regarded as an independent and legal system from a humanistic point of view. However, according to James
(1998: 17), learners were expected to conform to the standard of the target language, thought IL system has its own right to exist; if they violate well-known acceptable rules, it is definite that they commit errors, which is the fact even admitted by Corder (1971:150) as one of the pioneers who criticized error analysis. Ferris (2002) points out that the linguistic accuracy is of primary importance to formal situations such as application letters, commercial and political correspondence and the like.

However, other researchers argue for the comparability between IL and TL, and they object the claim that IL is one of natural languages (Birdsong, 1992; Schachter, 1990). According to James' description, ignorance of linguistic knowledge results in linguistic errors (1998: 62-63). It is widely agreed that there are two types of responses learners may deploy to compensate that ignorance: silence and substitution. In the case of silence, there are cultural silence and intended avoidance. When encountering avoidance, it is impossible for researchers and teachers to have a detailed and good observation on learner language. Fortunately, learners usually try to express themselves with substitutive means, which is indeed the object of EA. Furthermore, we know that adult FL learners are unlikely to attain NS-like competence. This universally existent state is labeled as incompleteness (James, 1998: 64), a term used to describe the general state of EFL learners' competence. It is different from the term ignorance which describes the specific state of one learner or groups of learners in their manifestation of control on the TL.

\section{B. Error types}

Ferris \& Roberts (2001) have pointed out that in previous research when categories of written errors were considered in analyzing the effects of provided feedback, there appeared to have significant difference in student performance and development across error categories (Chaney, 1999; Ferris, 1995; Ferris et al., 2000; Frantzen \& Rissell, 1987; Lalande, 1982; Sheppard, 1992). In Ferris (1999: 6), "treatable" errors were defined as those that "occur in a patterned, rule-governed way", and "untreatable" errors occur when "There is no handbook or set of rules students can consult to avoid or fix those types of errors". In other words, the former is susceptible to external intervention while the latter is relatively resistant. Ferris \& Roberts (2001) further studied the different ratios of error correction across five major error categories, i.e., verbs, noun endings, articles, word choice and sentence structure - the first three categories are regarded as "treatable", and the latter two as "untreatable". The results showed that error types were "reasonably" responsible to

Sponsors: Characteristic innovative projects of universities in Guangdong province (educational research projects), 2017GXJK226, Micro-lesson based Research on teaching mode of flipping English and American literature classroom; 2016GXJK203, Research on the validity of College Students' vocabulary memory from the perspective of Psycholinguistics. 
learner performance in error correction. All treatable errors were corrected at a higher ratio than untreatable errors. In addition, they found that untreatable errors to a considerable extent yielded to indirect feedback, a finding in contrast to suggestion from some previous relevant research (Chaney, 1999; Hendrickson, 1980).

\section{VARIOUS WAYS OF DEFINING FEEDBACK}

\section{A. ESL/EFL classroom orientation}

Lee (1997) distinguishes direct correction and indirect correction. Direct correction is overt, providing exact correction to errors, while indirect correction includes indication of many types to provide information about the location (e.g., underlining errors or erroneous sentences), the nature (e.g., correction code), and the number (in each line) of errors. Robb et al. (1986) included all of these four types of feedback, which were entitled as direct feedback (correction), uncoded in-text feedback (underline), coded in-text feedback (underline with codes) and marginal feedback (mark number of errors of each line), respectively. Ferris \& Roberts (2001) investigated two types of indirect feedback in their study, i.e., underling errors and underling errors without codes. Zhu and Wang (2005) followed the fashion though with slight difference. They include three types of feedback: underlining erroneous sentences, marking specific errors and providing metalinguistic clues (i.e., code) for erroneous sentences. The reason why this type of research is labeled as ESL/EFL classroom-oriented is that the participants in these studies are all from the actual classroom setting.

\section{B. Psycholinguistic perspective}

Ellis et al. (2006) distinguish explicit feedback and implicit feedback. Implicit feedback includes recast which provides positive and possibly negative evidence as some researchers argue. Explicit feedback includes explicit correction which provides both positive and negative evidence, and meta-linguistic feedback which indicates the nature of errors which is regarded as negative evidence. This meta-linguistic feedback is similar to previously mentioned coded feedback which indicates the nature of errors.

\section{Communicative orientation to language teaching (COLT)}

Lyster and Mori (2006) classify three types of feedback: explicit correction, recasts and prompts. Explicit correction and recasts provide learners with "target reformulations of their non-target output". The difference between them is that the former is direct while the latter is indirect to address learners the occurrence of non-target output. In their review, the authors include a range of feedback types under the label of prompts: elicitation, meta-linguistic clues, clarification requests and repetition. Here meta-linguistic clue is defined as "comments, information, or questions related to the well-formedness of the learner's utterance" (Lyster \& Ranta 1997: 47).

In surface, the definitions of feedback in the psycholinguistic school and the COLT context have something in common, e.g., both include the terms "explicit correction" and "meta-linguistic"; both are mainly adopted in the field of oral speech. But actually, the two schools have rather different focus. The former focuses on the distinctive and complementary function of explicitness and implicitness in terms of knowledge and learning (Ellis, 2004; Ellis, et al., 2006). The latter focuses on the functions of feedback in immersion classroom and task-basked classroom (both are communication-oriented) from a relatively intuitionist point of view. In contrast to these two types of definition, the ESL/EFL classroom orientation usually provides feedback on written output instead of oral speech. Obviously, this orientation is mainly based on classroom practice and appears to be relatively weak in the theoretical rationale it can rest on. Therefore in recent years some researchers (Ferris \& Roberts, 2001) have begun to take advantage of the relevant theoretical achievements such as "noticing the gap" (Schmidt, 1990) from the other two disciplines.

\section{STUdies About EFFeCTS OF CORRECTIVE FEEDBACK}

So far, as the issue of whether corrective feedback is beneficial to learners to perfect their output, there is still much dispute left. To settle this issue in detail, some researchers suggest considering whether there exist one or more than one type of more advantageous formal instruction (de Bot, et al, 2005). Some recent research served as typical examples (Iwashita 2003; Leeman 2003; Lyster 2004; McDonough 2005). Iwashita's study aims to explore the differential effects of negative feedback and positive evidence in task-based conversation on two Japanese structures' acquisitional development of L2 learners in Australian tertiary institution. Leeman explores the beneficial source of recast as one particularly prominent feedback in SLA research and hypothesizes that it is the positive evidence recasts carry with that brings its significant advantages over other negative feedback. Lyster purports to investigate the differential effects of prompts and recasts in form-focused instruction on immersion students' ability to accurately assign L2 French grammatical gender. Under the framework of output hypothesis, McDonough's goals are to recognize the impact of negative feedback and learners' responses on an ESL question development over an 8-week period. One common question arises as to what "negative feedback" entails and "positive evidence" means.

Compared with the method of giving explicit cues about nature of errors, indication of where an error locates appeared to be equally effective for student writers to edit their essays (Ferris \& Roberts, 2001; Zhu \& Wang, 2005). But the former seems to be more capable of deepening learners' attention to the weaknesses in their interlanguage system, thus probably promising a relatively longer-term effect on the development of learner language. In contrast to these two types of feedback, underlying erroneous sentences seems to be more indirect and obscure. Empirical research has shown that there was significant difference of its effect on both error location and error correction from that of other types of feedback such as specific marking (similar to underline) and metalinguistic clues (the nature of the error being provided but without location of where it is) (Zhu \& Wang, 2005). Their findings seem to confirm Ferris and Roberts's (2001) argument that the less explicit feedback is not only economical but also free from teachers' possible commitment of errors when they edit student compositions.

Relevant studies have explored the effects of different types of feedback from the teacher on students' performance to edit their written output (Robb, et al, 1986; Ferris \& Roberts 2001) and then the increasing quality of student composition "from one draft to the next" over the course of a semester (Lee, 1997; Fathman and Whalley, 1990; Chandler, 2003). The results are positive, i.e., teacher feedback can help improve students' performance in self-editing their drafts. Frantzen and Rissell (1987) found that errors labeled with certain linguistic categories were responded by students successfully within 10 minutes in the classroom, with $93 \%$ of marked errors being 
corrected. Fathman and Whalley (1990) have revealed that students with error feedback significantly outperformed those with content feedback in terms of the decrease of grammatical errors in their written production. Ferris (1997) examines the effects of two feedback types (marginal and end comments) on ESL student revision of draft essays in terms of their pragmatic goals and linguistic features. These findings indicate the importance of text-specific feedback provision.

Obviously, these studies have set out to explore the differential effects of various feedback types, only with no consistent and definite conclusion being drawn.

\section{CONCLUSIONS}

It is a prevalent phenomenon that L2 learners cannot attain an ideal level of grammatical competence. The situation is even worse for adult learners. Therefore, linguistic errors in output should be regarded as a reasonable consequence of learners putting formulated hypotheses on the aspects they feel uncertain and lack immediate help at the time of production, into testing circumstance in which learners may or may not notice the non-target forms by themselves. So errors are regarded as the unwanted features in learner language which should be dealt with by means of efficient ways (e.g., external supportive feedback).

It is supposed that whether students can catch these linguistic features will be influenced to a considerable extent by the feedback forms they have received, because the forms with different degrees of clarity may influence the learners' understanding of the problems under scrutiny. To be sure, there exists no definite type of error feedback that can benefit all learner groups in different contexts; therefore, when exploring the relatively advantageous effect of certain feedback types, the clear description of learners' proficiency level and the definition of key terms are inseparable parts to compare and interpret the research findings from the differential studies.

\section{REFERENCES}

[1] Allen, P., Swain, M, Harley, B \& Cummins, J. (1990). Aspects of classroom treatment: toward a more comprehensive view of second language education. In B. Harley, P. Allen, J. Cummins \& M. Swain (Eds.), The development of second language proficiency (pp. 58-81). Cambridge University Press.

[2] Birdsong, D. (1992). Ultimate attainment in second language acquisition. Language, 68, 4:706 - 748.

[3] Chaney, S. J. (1999). The effect of error types on error correction and revision. MA thesis, Department of English, Califormia State University, Sacramento.

[4] Corder, S.P. (1971). Idiosyncratic dialects and error analysis. International review of applied linguistics, 9, 2:147-60. Reprinted in S.P. Corder, 1981. Error Analysis and Interlanguage. Pp.14-25.

[5] De Bot, K., Lowie, W., \& Verspoor, M. 2005. Second language acquisition. Routledge.

[6] Ellis, R. (1984). Classroom second language development. Oxford: Pergamon.

[7] Ellis, R. (2004). The definition and measurement of L2 explicit knowledge. Language learning, 54 (2), 227-275.

[8] Ellis, R., Loewen, S., \& Erlam R. (2006). Implicit and explicit corrective feedback and the acquisition of L2 grammar. Studies in Second Language Acquisition, 28, 339-368.

[9] Fathman, A., \& Whalley, E. (1990). Teacher response to student writing: Focus on form versus content. In B. Kroll (Ed.), Second language writing: Research insights for the classroom (pp. 178-190). Cambridge: Cambridge University Press.

[10] Ferris, D. R. (1995). Can advanced ESL students be taught to correct their most serious and frequent errors? CATESOL Journal, 8 (1), 41-62.
[11] Ferris, D. R. (1999). The case for grammar correction in L2 writing classes: A response to Truscott (1996). Journal of Second Language Writing, 8, 1-10.

[12] Ferris, D. R. (2002). Treatment of error in second language student writing. The University of Michigan Press.

[13] Ferris, D. R. (2004). The "grammar correction" debate in L2 writing. Journal of Second Language Writing, 13, 49-62.

[14] Ferris, D. R., Chaney, S. J., Komura, K., Roberts, B. J., \& McKee, S. (2000). Does error feedback help student writers? New evidence on the short- and long-term effects of written error correction. Manuscript submitted for publication.

[15] Ferris, D. R., \& Roberts, B. (2001). Error feedback in L2 writing classes: How explicit does it need to be? Journal of second language writing, 10(3), 161-184.

[16] Hendrickson, J.M. (1980). The treatment of error in written work. Modern Language Journal, 64, 216-221.

[17] Iwashita, N. (2003). Negative feedback and positive evidence in task-based interaction. Studies in Second Language Acquisition, 25, $1-36$.

[18] James, C. (1998). Errors in language learning and use-Exploring error analysis. Addison Wesley Longman Limited.

[19] Lalande, J. F. (1982). Reducing composition errors: an experiment. Modern Language Journal 66, 140-149.

[20] Lee, I. (1997). ESL learners' performance in error correction in writing: Some implications for college-level teaching. System, 25, 465-477.

[21] Lyster, R., \& Mori, H. (2006). Interactional feedback and instructional counterbalance. Studies in Second Language Acquisition, 28, 269-300

[22] Lyster, R., \& Ranta, L. (1997). Corrective feedback and learner uptake: Negotiation of form in communicative classrooms. Studies in Second Language Acquisition, 19, 37-66.

[23] McDonough, K. (2005). Identifying the impact of negative feedback and learners' responses on ESL question development. Studies in Second Language Acquisition, 27, 79-103.

[24] Schachter, J. (1990) On the issue of completeness in second language acquisition. Second Language Research, 6, 93-124.

[25] Schmidt, R. W. (1990). The role of consciousness in second language learning. Applied Linguistics, 11, 127-158.

[26] Sheppard, K. (1992). Two feedback types: Do they make a difference? RELC Journal, 23, 103-110.

[27] Zhu and M. Wang. (2005). Feedback research in two language writing: form, clarity, and specific effects [J]. Modern Foreign Languages, 28 (2), 170-180. (In Chinese) 